\title{
Visually memorable neuroanatomy for beginners
}

\author{
Fabrice Duparc ${ }^{1}$ (D)
}

Received: 22 February 2021 / Accepted: 23 February 2021 / Published online: 6 March 2021

(c) The Author(s), under exclusive licence to Springer-Verlag France SAS part of Springer Nature 2021

Book review:

The authors propose this new book for beginners in Neuroanatomy.

Dr Min Suk Chung is Professor of Anatomy in Ajou University, South Korea. He has already published books including comics and cartoons for explaining and making easier the learning of Anatomy. Dr. Beom Sun Chung is a postdoctoral fellow in the Tulane Center for Clinical Neurosciences, Louisiana, USA, with a special interest in the stereoscopic models of the brain using reconstructions from the serially sectioned images of the Visible Korean Human.

The authors propose a global approach to Neuroanatomy, and include central nervous system (brain, spinal cord), peripheral nervous system and autonomic nervous system.

The books sections are:

1. Morphology of the central nervous system (brain, spinal cord, cavities, envelops).

2. Somatic nerve, autonomic nerve: motor nerve, sensory nerve, reflex arc; sympathetic and parasympathetic nerves and plexuses, with examples of functions.

3. Cranial nerve, spinal nerve: motor and sensory nerves, somatic and visceral.
4. Function of the brain: the main functions of the different parts of the brain and brainstem.

5. Development of the central nervous system: the evolution of the neural tube helps to understand and build the different parts of the central nervous system.

Most of the simple schemes could be used for introducing a course. Humorous and simple sentences make easy means for memorization.

The goal was to help students overcoming their "neurophobia", it should help to go ahead in this field of anatomical sciences. A great attention is constantly paid to the orientation of the anatomical views. An alphabetical index, from "Abdominal aorta" to "White ramus communicans" leads to a fast access to the different structures of the nervous system.

Some interesting ideas for simple and clear introduction to the learning of neuroanatomy are provided in this book, for beginners and those who teach them.

F Duparc.

Publisher's Note Springer Nature remains neutral with regard to jurisdictional claims in published maps and institutional affiliations.

Fabrice Duparc

fabrice.duparc@univ-rouen.fr

1 Laboratory of Anatomy, Faculty of Medicine, Rouen-

Normandy University, 22 Boulevard Gambetta,

76183 Rouen, France 